\title{
Mediatorless Impedance Studies with Titanium Dioxide Conjugated Gold Nanoparticles for Hydrogen Peroxide Detection
}

\author{
Nur Hamidah Abdul Halim ${ }^{1,2, *}$, Yook Heng Lee ${ }^{1}$, Radha Swathe Priya Malon Marugan ${ }^{1}$ \\ and Uda Hashim ${ }^{2}$ \\ 1 School of Chemical Sciences and Food Technology, Faculty of Science and Technology, Universiti \\ Kebangsaan Malaysia, Bangi 43600 UKM, Selangor, Malaysia; leeyookheng@yahoo.co.uk (Y.H.L.); \\ radhaswathepriya@gmail.com (R.S.P.M.M.) \\ 2 Institute of Nano Electronic Engineering, Universiti Malaysia Perlis, Kangar 01000, Perlis, Malaysia; \\ uda@unimap.edu.my \\ * Correspondence: nurhamidah@unimap.edu.my; Tel.: +60-3-8921-3356
}

Received: 20 June 2017; Accepted: 12 September 2017; Published: 18 September 2017

\begin{abstract}
An impedimetric-based biosensor constructed using gold nanoparticles (AuNP) entrapped within titanium dioxide $\left(\mathrm{TiO}_{2}\right)$ particles for hydrogen peroxide $\left(\mathrm{H}_{2} \mathrm{O}_{2}\right)$ detection is the main feature of this research. The matrix of the biosensor employed the surface of $\mathrm{TiO}_{2}$, which was previously modified with an amine terminal group using 3-Aminopropyltriethoxysilane (APTS) at a low temperature to create a ready to immobilise surface for the biosensor application. Hemoglobin $(\mathrm{Hb})$, which exhibits peroxidase-like activity, was used as the bioreceptor in the biosensor to detect $\mathrm{H}_{2} \mathrm{O}_{2}$ in solution. The analysis was carried out using an alternative impedance method, in which the biosensor exhibited a wide linear range response between $1 \times 10^{-4} \mathrm{M}$ and $1.5 \times 10^{-2} \mathrm{M}$ and a limit of detection (LOD) of $1 \times 10^{-5} \mathrm{M}$ without a redox mediator.
\end{abstract}

Keywords: impedimetric biosensor; mediatorless; direct electron transfer; aminated titanium dioxide; hemoglobin

\section{Introduction}

Hydrogen peroxide, $\mathrm{H}_{2} \mathrm{O}_{2}$, is commonly used as a food additive and preservative in food processing, such as in stored milk before cheese processing [1]. In the USA, it is classified to be unsafe if the $\mathrm{H}_{2} \mathrm{O}_{2}$ content is higher than $0.05 \%$ relative to the milk weight [2] or more than $14.6 \mu \mathrm{M}$ in milk samples if according to the FDA [3]. Therefore, the development of a biosensor that can detect $\mathrm{H}_{2} \mathrm{O}_{2}$ within a wide linear range response is of great significance for clinical, pharmaceutical, biochemical, environmental, and food analysis [4].

$\mathrm{TiO}_{2}$ is a multi-functional inorganic material that exhibits non-toxic properties, and is chemically inert and thermally stable when enhanced with other metals and semiconducting materials. Furthermore, high catalytic activities can be achieved using $\mathrm{TiO}_{2}$ with a large surface area in a dedicated synthesis method [5]. On the other hand, gold nanoparticles (AuNPs) are one of the noble metals, besides palladium and platinum, that have been well studied as an immobilization platform in biosensors due to their high conductivity and electro catalytic behavior [6]. AuNPs also offer a higher surface area compared to flat surface gold, thus allowing greater protein loading, and consequently, a more sensitive biosensor [6]. However, the aggregation between gold and the substrate material imposes an issue [7]. Thus, the stabilized citrate capped reduction method was proposed to prevent this issue [8].

It is noteworthy that the synthesis of a $\mathrm{TiO}_{2}$ sphere is complicated and difficult to control as the precursor of titanium (Ti) such as titanium isopropoxide (TTIP) is highly reactive in nature. On the 
other hand, gold colloids tend to agglomerate in alcoholic solution, which makes it harder to segregate it completely. In other words, an $\mathrm{Au} / \mathrm{TiO}_{2}$ nanocomposite is prone to rapid agglomeration and inhomogeneous particle distribution [9]. Although the synthesis of a gold core with a thin coating of $\mathrm{TiO}_{2}$ has been previously reported by [10], the nanocomposite has only been applied for photocatalytic applications. Furthermore, surface layer modification with an amine functional group on the titanium surface will lead towards better biomolecule immobilization. Although the composite of Ti and Au for biosensor applications has been reported in numerous publications, the construction of an impedimetric biosensor using both an $\mathrm{Au} / \mathrm{TiO}_{2}$ nanocomposite and enzyme has not been explored.

Throughout this time, the impedance method has been implemented as the support for biosensor analysis, also known to be a non-destructive characterisation [11]. Besides, the impedimetric methods in measuring an electrochemical biosensor have been applied to detect glucose content [12] and also in bacteria detection [13]. For the latter method, the impedance can be measured because of the metabolites coming from the growth of the bacteria itself. One of the advantages of this method is that it does not require a label especially for the DNA sensor. The impedance value is done by measuring the impedance change due to the target binding on the biorecepetor (either antibody or nucleic acid) that has been immobilised on the electrode surface.

However, this method is limited to detecting small analytes and metabolites and exposure to non-specific adsorption [14]. The application focuses on the detection of antibodies [15], bacteria [13], cholestrol [11,12], cancer cells [13,16], and DNA [17]. This EIS is mainly used for the surface characterisation of chemical sensors and biosensors and has been practised for a long time and is efficient for label-free detection, especially for a DNA biosensor [11,18]. Furthermore, in most impedance analysis redox couples such as ferricyanide/ferrocyanide, an electron acceptor for a heme containing enzyme [19] is often introduced but it may cause complications or interactions between the target molecule and probe surface [20].

In this study, AuNPs were entrapped within aminated $\mathrm{TiO}_{2}$ to ease the immobilization of the biomolecule in biosensor development. In addition, $\mathrm{Hb}$ was covalently attached onto the modified $\mathrm{TiO}_{2}$ surface. The AuNPs entrapped within $\mathrm{TiO}_{2}$ were modified, in which an amide bond was formed between the carboxyl end terminal of $\mathrm{Hb}$ and the amine terminal from TiAu-APTS. The TiAu-APTS is believed to provide catalytic properties towards the enzymatic sensor. It is also noteworthy that the impedimetric biosensor was developed without the usage of any redox mediators. In previous work, this conjugated TiAu-APTS was studied using the differential pulse voltammetry method with an acceptable linear range response towards the $\mathrm{H}_{2} \mathrm{O}_{2}$ concentration.

\section{Materials and Methods}

The precursor reagent for titanium dioxide particles was titanium isopropoxide (TTIP, 95\%). Absolute ethanol (99.5\%) was used as the main solvent. Ammonia (25\%) was used as the catalyst in this synthesis. 3-Aminopropyltriethoxysilane (APTS, 99\%), lyophilized human hemoglobin, gold chloride trihydrate $\left(\mathrm{HAuCl}_{4}, 49 \%\right), \mathrm{N}$-(3-Dimethylaminopropyl)-N'-ethylcarbodiimide hydrochloride (EDC), N-hydroxysuccinimide (NHS, 98\%), and 2-(N-Morpholino)ethanesulfonic acid (MES) hydrate buffer were purchased from Sigma Aldrich. Trisodium citrate dihydrate that was purchased from Systerm was used for the preparation of the Au colloid. All the chemicals purchased were of analytical grade and used without further purification. The phosphate buffer solution was prepared by mixing disodium phosphate $\left(\mathrm{Na}_{2} \mathrm{HPO}_{4}\right)$ and sodium dihydrogen phosphate $\left(\mathrm{NaH}_{2} \mathrm{PO}_{4}\right)$. Deionized water (DIW, $18 \mathrm{M} \Omega \mathrm{cm}$ ) was used throughout this experiment.

TiAu-APTS was prepared using a slight modification of a method reported before [21-23], with $\mathrm{TiO}_{2}$ conjugated with the Au colloid and later functionalized with APTS (Additional Supplementary Data). The morphology of TiAu-APTS was then observed under a Field Emission Electron Microscope (FESEM) and Transmission Electron Microscope (TEM).

The fabrication steps of the electrode $\mathrm{Hb} / \mathrm{TiAu}$-APTS/SPE are illustrated in Figure $1 \mathrm{a}$. A TiAu-APTS colloid of $15 \mu \mathrm{L}$ was dropped onto the SPE and left to dry at room temperature. 
$\mathrm{Hb}$ was first activated separately using EDC (0.02 M) and NHS (0.004 M) in MES buffer (pH 6.85) at room temperature. Subsequently, the prior prepared TiAu-APTS/SPE was immersed into the activated $\mathrm{Hb}$ in EDC/NHS for nine hours immobilisation. The $\mathrm{Hb} / \mathrm{TiAu}-\mathrm{APTS} / \mathrm{SPE}$ was rinsed thoroughly before analysis. All the experiments were carried out using CV and EIS methods in 0.05 M Na PBS ( $\mathrm{pH}$ 7), unless otherwise stated.

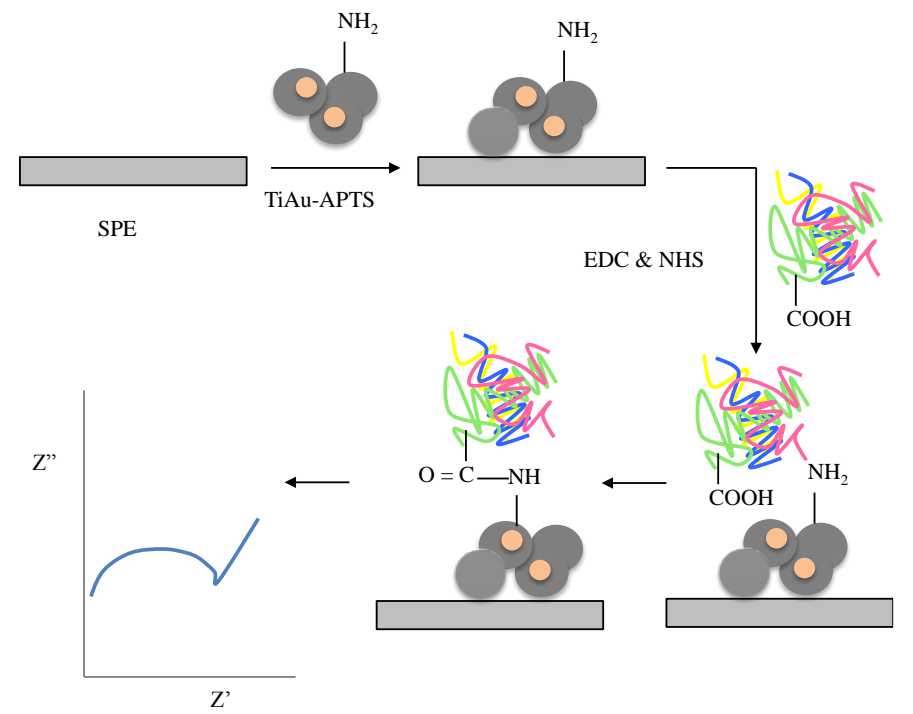

(a)

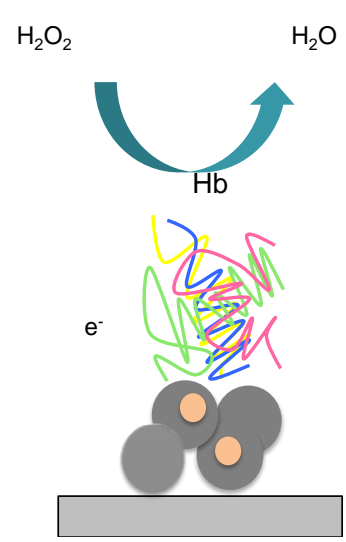

(b)

Figure 1. (a) Fabrication steps and (b) mechanism of the Hb/TiAu-APTS/SPE impedance biosensor using the EDC-NHS route for $\mathrm{Hb}$ immobilization on the modified electrode.

An AutoLAB potentiostat PGSTAT 12 (Metrohm) was used to perform all the electrochemical measurements. It includes a modified carbon Screen printed electrode (SPE) (Scrint Technology (M) Sdn. Berhad), Pt electrode, and $\mathrm{Ag} / \mathrm{AgCl}$ (in saturated $\mathrm{KCl}$ ) electrode as the working, counter, and reference electrodes, respectively. The Cyclic Voltammetry (CV) and Differential Pulse Voltammetry (DPV) were conducted to observe the electrochemical behavior of modified electrodes in both buffer $(0.05 \mathrm{M}$, $\mathrm{pH} 7.0)$ and potassium ferricyanide $(5 \mathrm{mM})$ solution. The $\mathrm{CV}$ experiments were carried out versus the $\mathrm{Ag} / \mathrm{AgCl}$ reference electrode at room temperature $\left(25^{\circ} \mathrm{C}\right)$ at a scan rate of $100 \mathrm{mV} / \mathrm{s}$. Electrochemical Impedance Spectroscopy (EIS) measurements were performed at frequencies from $100 \mathrm{kHz}$ to $100 \mathrm{~Hz}$ with an amplitude (0.1) to the open circuit potential (OCP) in buffer solution. The impedance results were recorded at a DC potential of $\pm 200 \mathrm{mV}$ and the impedance spectrum was acquired at seven minutes. The calibration curve was produced by preparing 30 SPEs at various concentrations of $1 \times 10^{-6}$ to $1.5 \times 10^{-2} \mathrm{M} \mathrm{H}_{2} \mathrm{O}_{2}$ using the $\mathrm{Hb} / \mathrm{TiAu}$-APTS/SPE electrode.

\section{Results and Discussion}

\subsection{Characterization of TiAu-APTS}

The TiAu-APTS on the electrode was characterized using FESEM and TEM, as shown in Figure $2 \mathrm{a}, \mathrm{b}$, respectively. It was observed that the TiAu-APTS particles were of a non-uniform shape with submicron sizes of less than $1 \mu \mathrm{m}$. The EDX spectrum shows the elements of $\mathrm{Ti}, \mathrm{SiO}$, and Au on the surface of TiAu-APTS. The Si was observed due to the silane group derived from APTS during the synthesis. From the TEM observation, it was observed that the Au NPs were trapped within $\mathrm{TiO}_{2}$ particles. The faint image of AuNPs is due to the thick particles of the amorphous $\mathrm{TiO}_{2}$ blocking transmission of the electron of the AuNP. The TiAu produced AuNPs with a size of 4-5 nm, which is much smaller than the average size of the AuNP colloid of $\pm 38.85 \mathrm{~nm}$ before the synthesis 
took place. The $\mathrm{TiO}_{2}-\mathrm{Au}$ conjugate is proportionately bigger in size with thicker $\mathrm{TiO}_{2}$ amorphous particles and reduced Au colloid sizes. The change in the Au size happened due to the addition of ammonia during the synthesis that gradually changes the $\mathrm{pH}$ of the solution to become more basic, thus reducing the size of AuNP. The size reduction of AuNP due to the $\mathrm{pH}$ solution is in agreement with Brinas et al., 2008 [24].

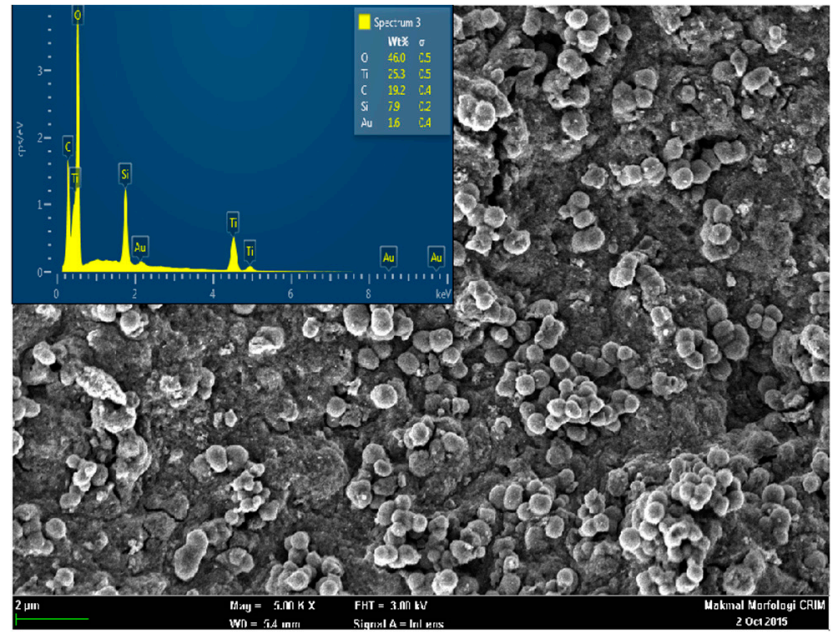

(a)

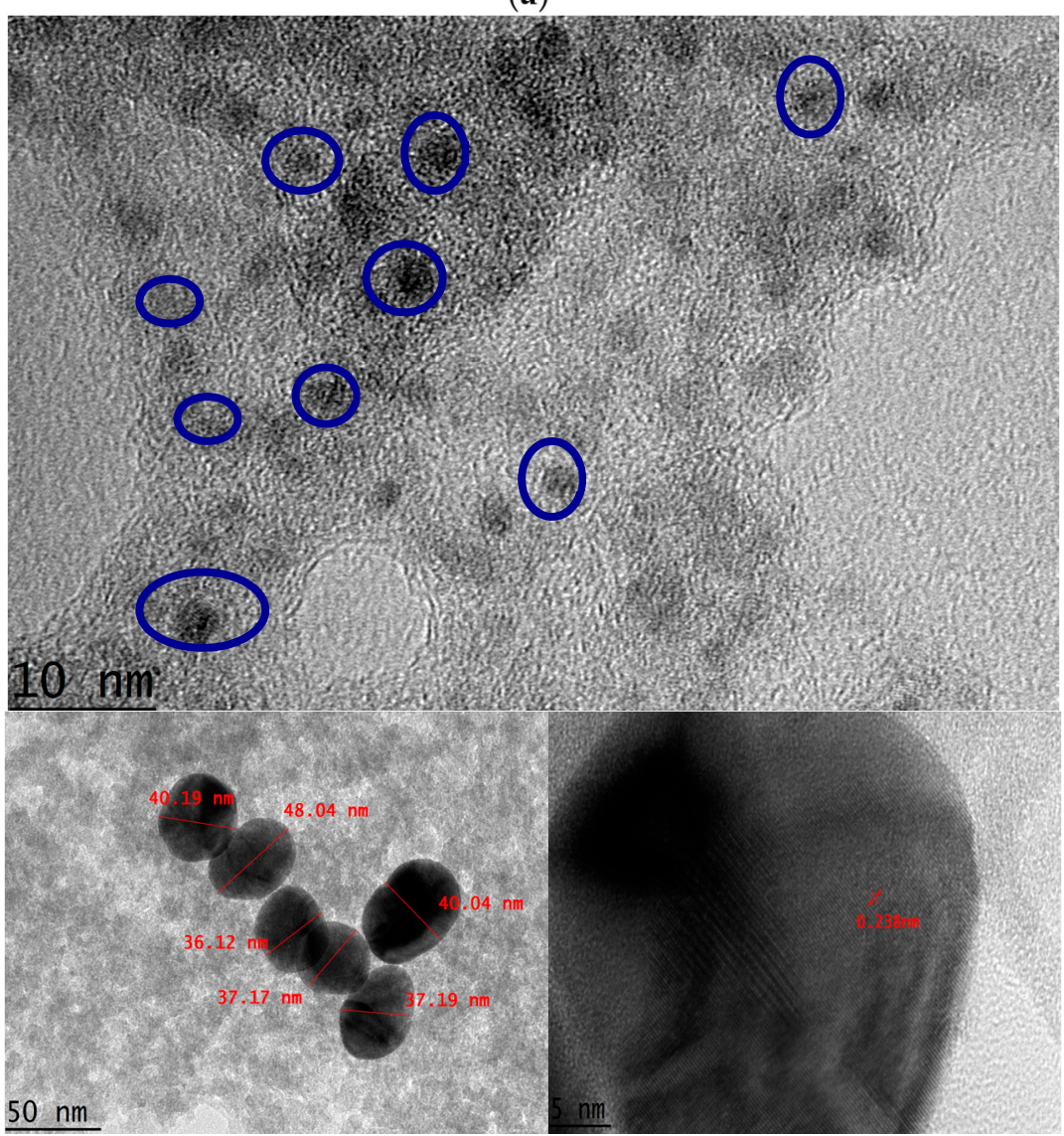

(b)

Figure 2. (a) TiAu-APTS under SEM with the inset of EDX spectrum and (b) Morphology of TiAu-APTS under TEM. The blue circle shows the Au colloid that is embedded with $\mathrm{TiO}_{2}$ particles in an amorphous state. The bottom left inset is an Au nano colloid with $\mathrm{TiO}_{2}$ particles. The bottom right inset shows the Au nano colloid crystal with $d=0.2368 \mathrm{~nm}$. 


\subsection{Characterization of AuNPS/SPE and TiAu-APTS/SPE Electrode}

First, Na PBS $(0.05 \mathrm{M}, \mathrm{pH} 7.4,0.075 \mathrm{NaCl})$ was used to study the characteristics of $\mathrm{Hb} / \mathrm{TiAu}-\mathrm{APTS} / \mathrm{SPE}$. Figure 3a shows the CV of SPE, TiAu-APTS/SPE, and $\mathrm{Hb} / \mathrm{TiAu}-\mathrm{APTS} / \mathrm{SPE}$ in Na PBS. It can be observed that the oxidation peak for the SPEs that were immobilised with $\mathrm{Hb}$ ( $\mathrm{Hb}$ /TiAu-APTS/SPE) was higher compared to TiAu-APTS/SPE. This confirmed that $\mathrm{Hb}$ was succesfully immobilised on the SPE due to the presence of the reduction peak at approximately $-0.3 \mathrm{~V}$, which is in agreeement with [25]. The oxidation peak values were $\mathrm{Hb} / \mathrm{Au} / \mathrm{SPE}>\mathrm{Hb} / \mathrm{SPE}$ $>\mathrm{Hb} / \mathrm{TiAu}$-APTS/SPE. The low oxidation peak value was due to the semiconductive properties of TiAu-APTS in buffer solution and the absence of a redox probe such as ferricyanide $\left(\left[\mathrm{Fe}(\mathrm{CN})_{6}\right]^{3-}\right)$. The electron transfer rate in Na PBS is also slow as the anodic and cathodic peak separation value $(\triangle \mathrm{Ep})$ is $450 \mathrm{mV}$. In comparison, Figure $3 \mathrm{~b}$ shows the $\mathrm{CV}$ of the modified SPEs in a conductive solution containing potassium ferricyanide $\left(\mathrm{K}_{3}\left[\mathrm{Fe}(\mathrm{CN})_{6}\right]\right)$ as the redox probe. AuNPs are well known for their excellence conductivity, and are introduced to enhance the semiconducting properties of $\mathrm{TiO}_{2}$. This AuNP embedded inside the titanium oxide demonstrated better electron transfer as TiAu-APTS/SPE resulted in a better electron transfer rate $(\triangle \mathrm{Ep}$ of $279 \mathrm{mV})$ compared to the Au/SPE electrode $(\triangle \mathrm{Ep}$ of $559.6 \mathrm{mV})$.

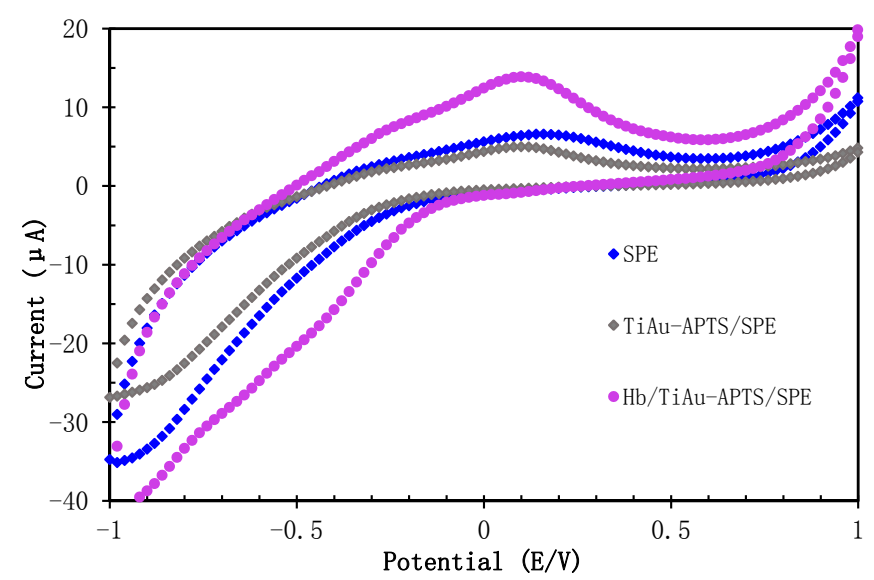

(a)

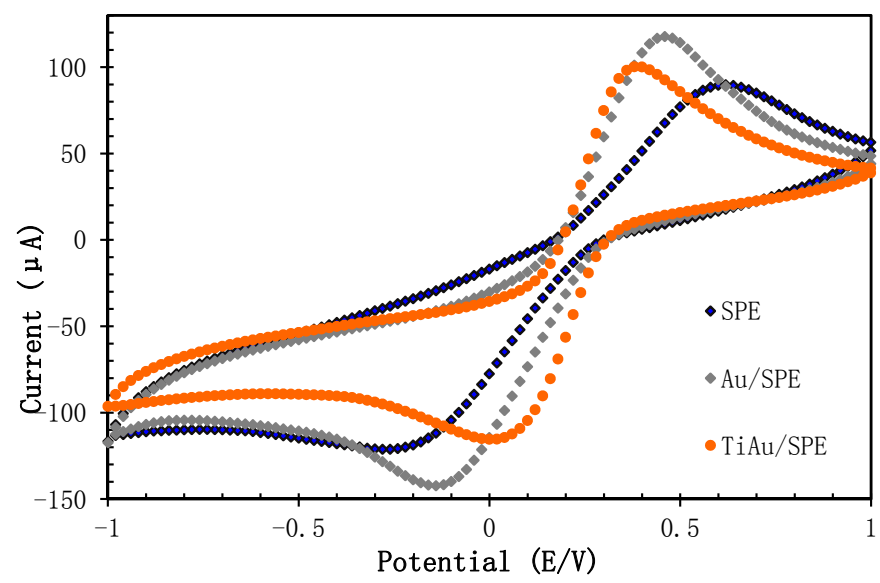

(b)

Figure 3. Electrochemical study of different modified SPEs in (a) $0.1 \mathrm{M} \mathrm{PBS}(0.1 \mathrm{M} \mathrm{NaCl}, \mathrm{pH} 7.4)$ and (b) in $5 \mathrm{mM} \mathrm{K}_{3}\left[\mathrm{Fe}(\mathrm{CN})_{6}\right]$ solution.

Figure 4 shows a Nyquist plot for the surface study of SPE, Au/SPE, TiAu-APTS/SPE, and $\mathrm{Hb} / \mathrm{TiAu}$-APTS/SPE electrodes in Na PBS. It can be observed that bare SPE has a higher electron 
charge transfer resistance $\left(\mathrm{R}_{\mathrm{CT}}\right)$ value compared to $\mathrm{Au} / \mathrm{SPE}$ and $\mathrm{Hb} / \mathrm{TiAu}-\mathrm{APTS} / \mathrm{SPE}$, but a lower $\mathrm{R}_{\mathrm{CT}}$ value than TiAu-APTS/SPE. The $Z^{\prime}$ value that is derived from the semi-circle axis also represented by $R_{C T}$ represents the kinetic electron transfer value of the interface electrode [11]. The lowest impedance value $(369 \Omega)$ was obtained from Au/SPE due to the highly conductive property of gold that lowers the resistance on the electrode surface. On the other hand, TiAu-APTS/SPE has the highest impedance value ( $401 \Omega$ ) due to the poor electrical conductivity of TiAu-APTS/SPE. However, when $\mathrm{Hb}$ was immobilized on the TiAu-APTS/SPE ( $\mathrm{Hb} / \mathrm{TiAu}-\mathrm{APTS} / \mathrm{SPE})$, it gives a lower impedance value $(372 \Omega$ ) than TiAu-APTS/SPE because the immobilized protein has good conformation and is capable of maintaining its natural activity in a suitable condition [11]. The low impedance value in $\mathrm{Hb} / \mathrm{TiAu}-\mathrm{APTS} / \mathrm{SPE}$ reflects the low resistivity and better current penetration of the electrode in mediatorless buffer solution.

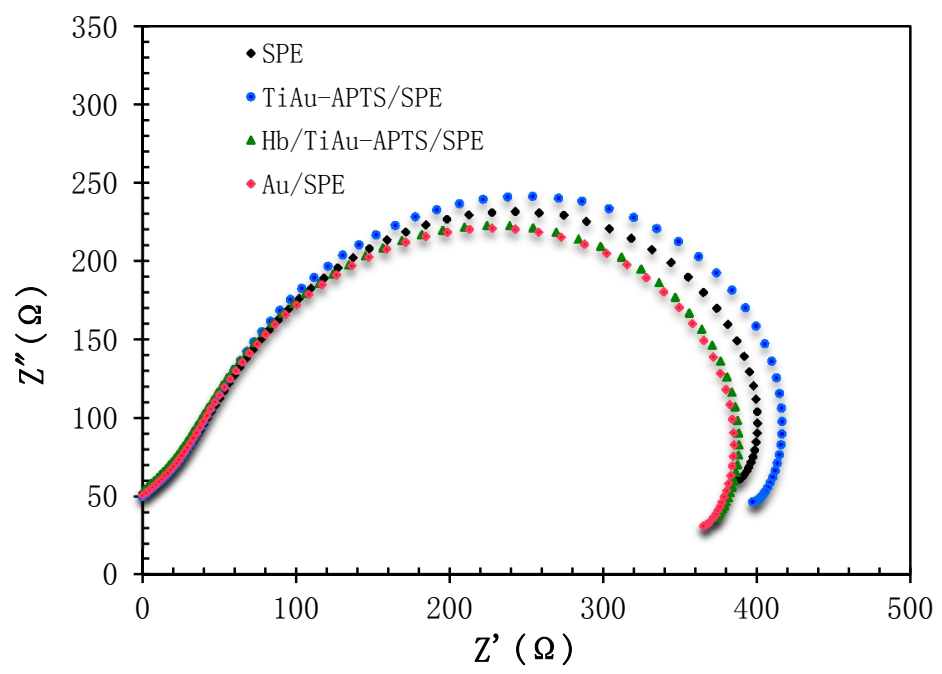

Figure 4. The Nyquist plot of different modified SPEs in PBS (0.1 M NaCl, pH 7.4).

In impedance analysis, high impedance values are obtained when electrodes with a similar charge repel each other in the interface between the bulk solution and surface of the electrode. Unlike amperometric analysis, the mechanism of the redox process in impedance analysis is still unclear. Hence, the impedance value of a conductive material depends on the optimum size and quantity that can either reduce or increase the impedance due to the repelling charge effect. When similar charges are built up on the surface of the electrode, a diffusion process can develop for charge transfer resistance $\left(R_{C T}\right)$, and the process of electrons moving to the electrode surface becomes slower, thus increasing the $\mathrm{R}_{\mathrm{CT}}$ values [18]. It is important to have an optimum $\mathrm{Hb}$ immobilized on the modified electrode surface that results in enough electron transfer and avoids creating a repelling charge effect that increases the $\mathrm{R}_{\mathrm{CT}}$ value.

\subsection{Performances of Biosensor}

$\mathrm{H}_{2} \mathrm{O}_{2}$ concentrations in the range between $5 \times 10^{-1} \mathrm{M}$ and $5 \times 10^{-10} \mathrm{M}$ were used to determine the preliminary dynamic range of the $\mathrm{Hb} / \mathrm{TiAu}$-APTS/SPE biosensor. Figure 5 a shows the Nyquist plot for different $\mathrm{H}_{2} \mathrm{O}_{2}$ concentrations. The Nyquist plot consists of two significant parts that are a semicircle and linear part that are represented by an electrode interface on the surface and electrode diffusion layer, respectively. The value represents the kinetic electron transfer of the redox probe at the electrode interface [11]. The $\mathrm{R}_{C T}$ value was lower at higher concentrations of $\mathrm{H}_{2} \mathrm{O}_{2}$ and this finding was supported by $[26,27]$. 


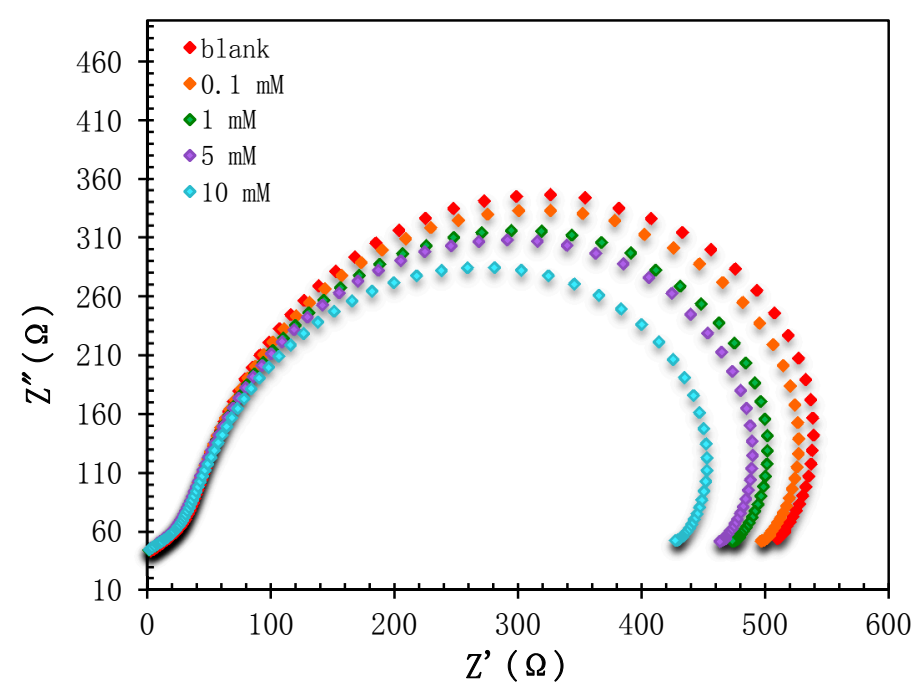

(a)

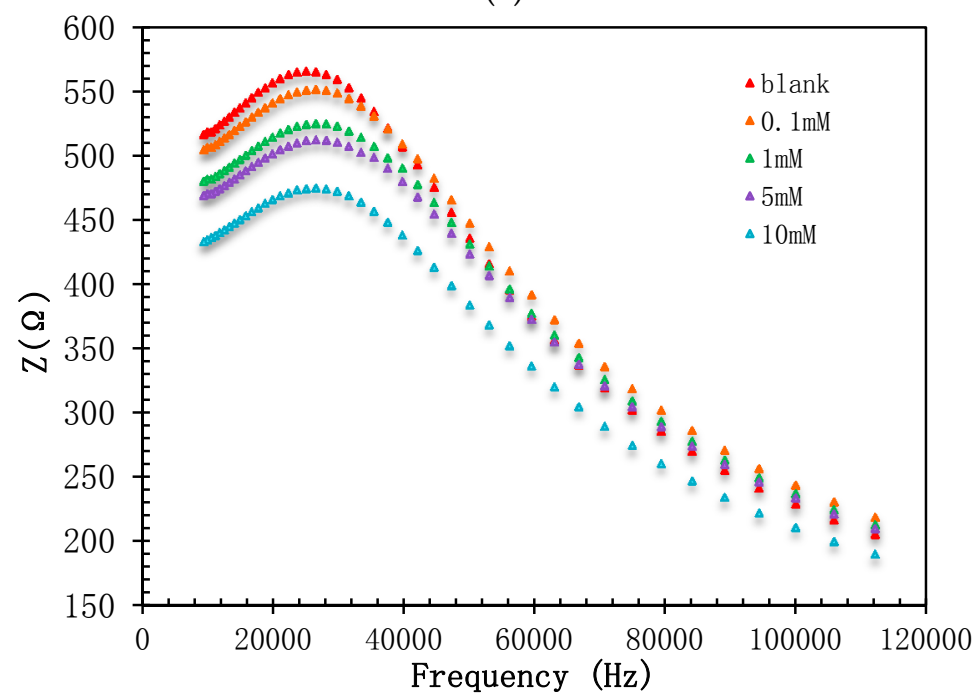

(b)

Figure 5. The (a) Nyquist and (b) Bode modulus plot for the Hb/TiAu-APTS/SPE biosensor at different $\mathrm{H}_{2} \mathrm{O}_{2}$ concentrations.

Lin et al. [27] reported a linear range for $\mathrm{H}_{2} \mathrm{O}_{2}$ detection between $4 \times 10^{-5}$ and $1 \times 10^{-4} \mathrm{M}$ with a low LOD of $2 \times 10^{-6} \mathrm{M}$, where the response time was 30 to $40 \mathrm{~min}$. However, for this $\mathrm{Hb} / \mathrm{TiAu}-\mathrm{APTS} / \mathrm{SPE}$ biosensor, the response time was $3 \mathrm{~min}$. The low $\mathrm{R}_{\mathrm{CT}}$ is believed to occur because of the production of an $\mathrm{H}^{+}$proton in the measurement solution [28] whenever $\mathrm{Hb}$ was reacted with a higher concentration of $\mathrm{H}_{2} \mathrm{O}_{2}$. In the absence of electron mediator $\left[\mathrm{Fe}(\mathrm{CN})_{6}\right]^{3-/ 4-}$, the performance of the $\mathrm{Hb} / \mathrm{TiAu}-\mathrm{APTS}$ biosensor was in agreement with the mechanism reported [29], as depicted in Figure $1 \mathrm{~b}$. The impedance $\mathrm{R}_{\mathrm{CT}}$ value may increase or decrease depending on the difference in the charge on the surface of the electrodes and solution. At low $\mathrm{H}_{2} \mathrm{O}_{2}$ concentrations, the $\mathrm{R}_{\mathrm{CT}}$ value was at the highest because electron movement was blocked. On the other hand, at a high $\mathrm{H}_{2} \mathrm{O}_{2}$ concentration, a low impedance value was recorded, which indicated that electrons passing through the modified electrode were not blocked. This result was in agreement with the trends reported in [30], where the $\mathrm{R}_{\mathrm{CT}}$ value decreased with increasing $\mathrm{H}_{2} \mathrm{O}_{2}$ concentrations. The resistivity of the film becomes greater whenever $\mathrm{H}_{2} \mathrm{O}_{2}$ is at a low concentration.

The bode modulus was plotted as shown in Figure $5 \mathrm{~b}$ to observe the impedance change, $\mathrm{Z}$ or constant phase element, and CPE against the frequency. The plot was important because impedance is 
not solely determined based on the $\mathrm{R}_{\mathrm{CT}}$ value, but also on the frequency position during the reaction. From the plot, it can be observed that the frequency was recorded from 26 to $28 \mathrm{kHz}$.

Based on Figure 6, the linear range for the $\mathrm{Hb} / \mathrm{TiAu}-\mathrm{APTS} / \mathrm{SPE}$ biosensor was recorded between $1 \times 10^{-4}$ and $1.5 \times 10^{-2} \mathrm{M}$ with a low LOD of $1 \times 10^{-5} \mathrm{M}$. The linear range was narrower than reported in [7] between $1 \times 10^{-5}$ and $22.3 \times 10^{-3} \mathrm{M}$. Regardless, this $\mathrm{Hb} / \mathrm{TiAu}$-APTS/SPE biosensor gave a better response than the enzymeless $\mathrm{TiO}_{2}-\mathrm{Ag}$ biosensor reported by [7], which only had an LOD of $5 \times 10^{-4} \mathrm{M} \mathrm{H}_{2} \mathrm{O}_{2}$. Overall, the performance of this $\mathrm{Hb} / \mathrm{TiAu}$-APTS/SPE biosensor was less sensitive compared to the amperometry method due to its narrow linear range, but it can be used as an alternative method to qualitatively support an amperometry biosensor on the electrode surface considering that the diffusion process in kinetic and mass transfer is limited. The measurement in the absence of redox mediator $\left[\mathrm{Fe}(\mathrm{CN})_{6}\right]^{3-/ 4-}$ produced a narrow linear range response, yet still managed to detect the analyte.

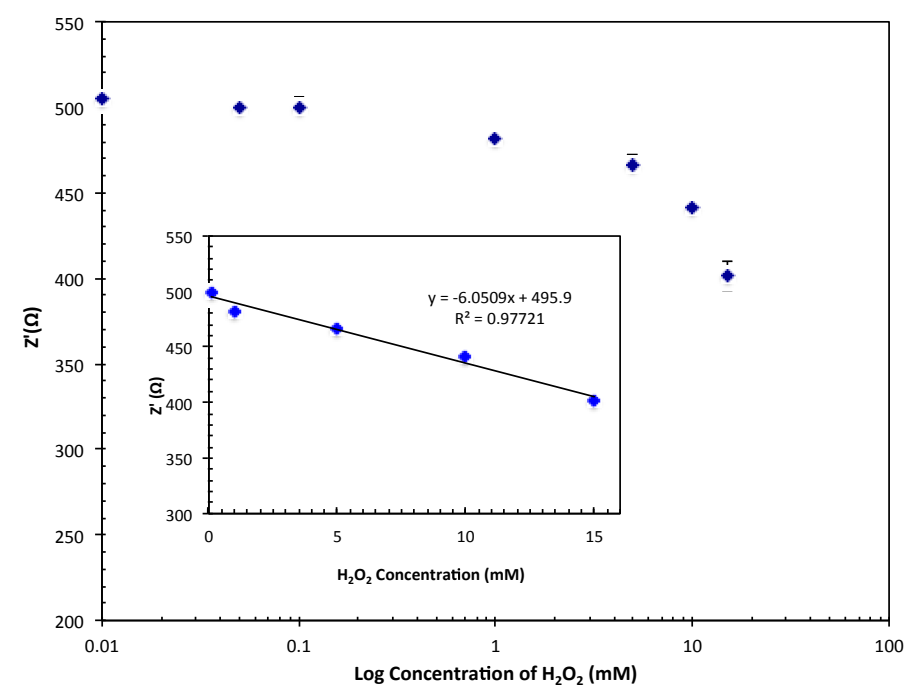

Figure 6. The response linear range of $\mathrm{Hb} / \mathrm{TiAu}-\mathrm{APTS} / \mathrm{SPE}$ biosensors towards various $\mathrm{H}_{2} \mathrm{O}_{2}$ concentrations.

In addition, an interference study was conducted using common interferences from electroactive species such as ascorbic acid and glucose at three different ratios to observe the selectivity of the biosensor, and no significant interferences were observed in Table 1 as small changes in $R_{C T}$ within experimental errors were obtained when the interferants were introduced. However, electroactive species such as ascorbate act as molecular oxygen activators producing free radicals [31] if combined with radical $\mathrm{H}_{2} \mathrm{O}_{2}$, creating interference towards the response of a biosensor at a much higher concentration of $\mathrm{H}_{2} \mathrm{O}_{2}$.

Table 1. Interference study on the $\mathrm{Hb} / \mathrm{TiAu}-\mathrm{APTS} / \mathrm{SPE}$ biosensor towards glucose and ascorbic acid with $1 \mathrm{mM} \mathrm{H}_{2} \mathrm{O}_{2}$ at different ratios $(n=3)$.

\begin{tabular}{cccc}
\hline \multirow{2}{*}{ Ratio of Interference to Analyte } & $\begin{array}{c}\text { Glucose Impedance Value } \\
\left(\mathbf{R}_{\mathbf{C T}}\right)\end{array}$ & \% Change & $\begin{array}{c}\text { Ascorbic Acid Impedance Value } \\
\left(\mathbf{R}_{\mathbf{C T}}\right)\end{array}$ \\
\hline High (10:1) & 433.67 & -1.66 & 408.00 \\
Medium (1:1) & 419.67 & -2.18 & 414.67 \\
Low (0.1:1) & 417.33 & -2.72 & 438.33 \\
\hline
\end{tabular}

From the Nyquist plot, the $\mathrm{R}_{\mathrm{CT}}$ value on the $x$-axis and $y$-axis refers to the resistance and capacitance value, respectively. In comparison to the DPV method, the impedance can be regarded as the reciprocal of the current value in the electrochemical measurement. As in the electrochemical measurement, the reactions of different analytes occur at a specific potential. However, in impedimetric 
measurements, the frequency is also important to qualitatively determine the response of different analytes for developing biosensors. However, the drawback of the impedance analysis method using a single frequency is its slow response compared to the amperometry method [12].

A commercial milk sample was used to validate the accuracy of this $\mathrm{Hb} / \mathrm{TiAu}-\mathrm{APTS} / \mathrm{SPE}$ biosensor method with the standard method. When $\mathrm{Hb}$ was exposed to a real sample of diluted milk in the ratio of 1:11, the frequency was recorded at $33.5 \mathrm{kHz}$, but the frequency shifted to $26.6 \mathrm{kHz}$ in buffer solution, as shown in Figure $7 \mathrm{a}$. Figure $7 \mathrm{~b}$ shows the equivalent circuit that represents the $\mathrm{Hb} / \mathrm{TiAu}$-APTS/SPE biosensor. The circuit is constructed from a resistor, $\mathrm{R}_{\mathrm{S}}$, which is connected to a parallel resistor and inductor, L, with CPE and Warburg impedance, and finally with another $\mathrm{CPE}$ element. The inductance may be derived from the magnetic effect of the $\mathrm{Fe}^{3+}$ ion inside $\mathrm{Hb}$ to form an inductor in the system. However, there might be a possibility that the inductor is not a real inductor, but from a resistor and capacitor. Table 2 shows the recovery results for the commercial milk sample at four different $\mathrm{H}_{2} \mathrm{O}_{2}$ concentrations. The recovery of this biosensor within the range of 90 to $114 \%$ at four different $\mathrm{H}_{2} \mathrm{O}_{2}$ concentrations is acceptable for the recovery of milk analysis reported by Dong et al., which was reported to be between $94.3 \%$ and $119 \%$ at LOD $3.3 \mu \mathrm{M}$ [2].

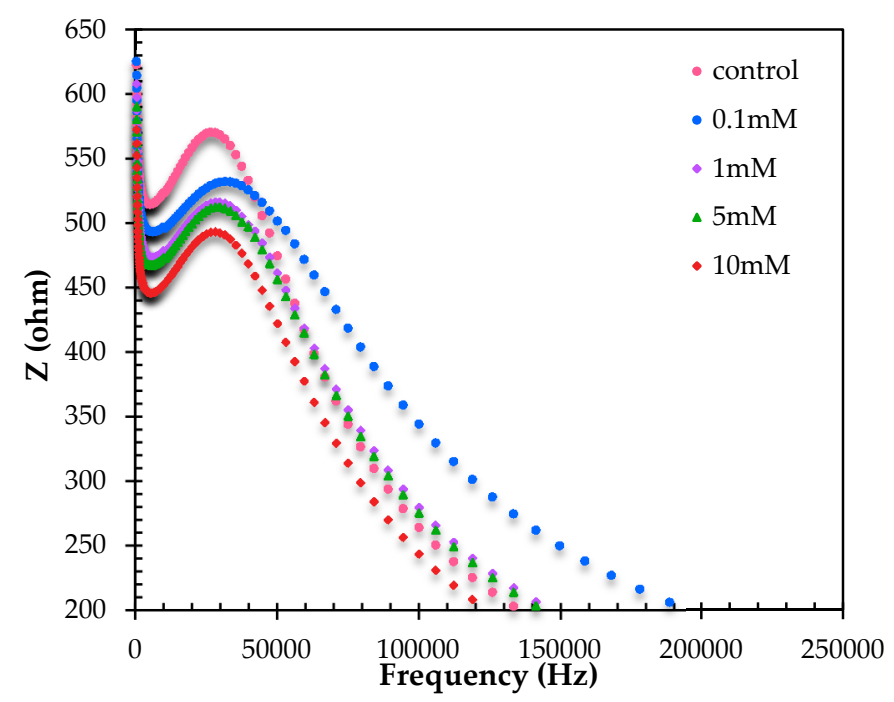

(a)

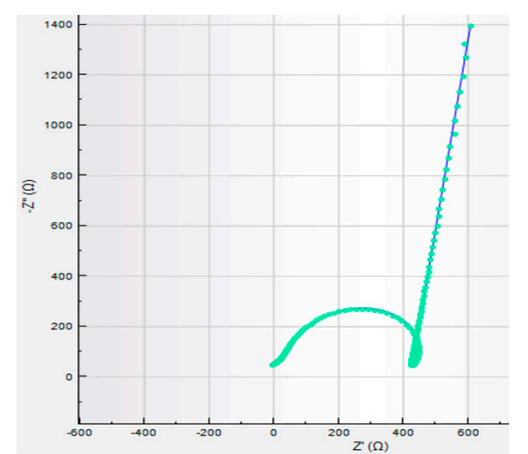

(b)

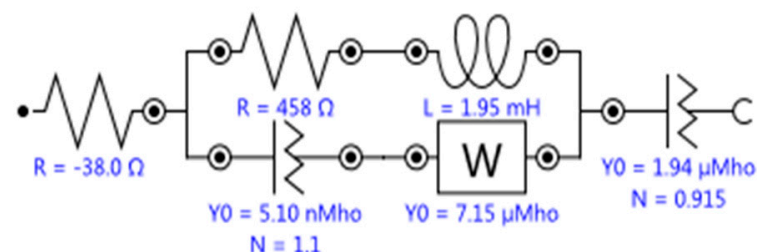

(c)

Figure 7. The (a) Bode modulus plot for the real milk sample at $33.5 \mathrm{kHz}$ and (b) Nyquist plot of the real and (c) fitted equivalent circuit to represent the impedance biosensor of the $\mathrm{Hb} / \mathrm{TiAu}-\mathrm{APTS} / \mathrm{SPE}$ biosensor with $\chi^{2} \leq 0.1$. 
Table 2. Recovery of the milk sample for the $\mathrm{Hb} / \mathrm{TiAu}$-APTS biosensor in $\mathrm{H}_{2} \mathrm{O}_{2}$ detection $(n=3)$ with $\mathrm{RSD}=6 \%$.

\begin{tabular}{ccc}
\hline Added $\mathbf{H}_{\mathbf{2}} \mathbf{O}_{\mathbf{2}} \mathbf{( m M )}$ & Found in Milk Sample & Recovery $\%$ \\
\hline 1 & 1.14 & 114 \\
5 & 4.94 & 98 \\
10 & 9.02 & 90 \\
15 & 15.63 & 104 \\
\hline
\end{tabular}

\section{Conclusions}

This $\mathrm{Hb} / \mathrm{TiAu}-\mathrm{APTS} / \mathrm{SPE}$ biosensor with impedance detection demonstrated a satisfactory linear range response for $\mathrm{H}_{2} \mathrm{O}_{2}$ detection with a good resistance to interference. The mediatorless impedance biosensor with an LOD of $1 \times 10^{-5} \mathrm{M}$ and a reproducibility of $5 \%(n=3)$ shows enhancement in the ability of $\mathrm{H}_{2} \mathrm{O}_{2}$ to be detected in the milk sample within the range of the safety limit of $14.6 \mu \mathrm{M}$ according to the FDA. Even though the demonstrated process was tedious, it opens up the challenge to explore impedimetric areas in biosensing. This biosensor also demonstrated the ability of $\mathrm{Hb}$ to be immobilised solely on the TiAu-APTS surface, and the change in the biomolecule charge in $\mathrm{Hb}$ during exposure to analyte was thus successfully observed through this impedance study.

Supplementary Materials: The following are available online at www.mdpi.com/2079-6374/7/3/38/s1.

Acknowledgments: This work has been supported by Universiti Kebangsaan Malaysia via grants DPP-2017-064 (Chemical Sensor and Biosensor Research Group) and GP-5179-2017.

Author Contributions: Nur Hamidah Abdul Halim conceived, designed, and performed the experiments; Nur Hamidah Abdul Halim and Lee Yook Heng analyzed the data; Lee Yook Heng and Uda Hashim contributed reagents/materials/analysis tools; Nur Hamidah Abdul Halim wrote the paper; Lee Yook Heng and Radha Swathe Priya Malon Marugan edited the paper.

Conflicts of Interest: The authors declare no conflict of interest.

\section{References}

1. Peng, C.; Liu, C.; Xie, Z. Preparation of a fluorescent silver nanoprism-dye complex for detection of hydrogen peroxide in milk. Anal. Methods 2015, 7, 9749-9752. [CrossRef]

2. Dong, X.-X.; Li, M.-Y.; Feng, N.-N.; Sun, Y.-M.; Yang, C.; Xu, Z.-L. A nanoporous MgO based nonenzymatic electrochemical sensor for rapid screening of hydrogen peroxide in milk. RSC Adv. 2015, 5, 86485-86489. [CrossRef]

3. Thandavan, K.; Gandhi, S.; Nesakumar, N.; Sethuraman, S.; Rayappan, J.B.B.; Krishnan, U.M. Hydrogen peroxide biosensor utilizing a hybrid nano-interface of iron oxide nanoparticles and carbon nanotubes to assess the quality of milk. Sens. Actuators 2015, 215, 166-173. [CrossRef]

4. Chen, C.; Hong, X.; Xu, T.; Chen, A.; Lu, L.; Gao, Y. Synthetic Metals. Synth. Met. 2016, 212, $123-130$. [CrossRef]

5. Hussain, M.; Tariq, S.; Ahmad, M.; Sun, H.; Maaz, K.; Ali, G. Ag-TiO 2 nanocomposite for environmental and sensing applications. Mater. Chem. Phys. 2016, 181, 194-203. [CrossRef]

6. Li, Y.; Schluesener, H.J.; Xu, S. Gold nanoparticle-based biosensors. Gold Bull. 2011, 43, 29-41. [CrossRef]

7. Huang, S.; Si, Z.; Li, X.; Zou, J.; Yao, Y.; Weng, D. A novel Au/r-GO/TNTs electrode for $\mathrm{H}_{2} \mathrm{O}_{2}, \mathrm{O}_{2}$ and nitrite detection. Sens. Actuators B Chem. 2016, 234, 264-272. [CrossRef]

8. Zheng, L.Q.; Yu, X.D.; Xu, J.J.; Chen, H.Y. Colorimetric detection of quaternary ammonium surfactants using citrate-stabilized gold nanoparticles (Au NPs). Anal. Methods 2014, 6, 2031-2033. [CrossRef]

9. Bian, Z.; Zhu, J.; Cao, F.; Lu, Y.; Li, H. In situ encapsulation of Au nanoparticles in mesoporous core-shell $\mathrm{TiO} 2$ microspheres with enhanced activity and durability. Chem. Commun. 2009, 25, 3789-3791. [CrossRef] [PubMed]

10. Seh, Z.W.; Liu, S.; Han, M.-Y. Titania-Coated Metal Nanostructures. Chem. Asian J. 2012, 7, $2174-2184$. [CrossRef] [PubMed] 
11. Kaushik, A.; Solanki, P.R.; Kaneto, K.; Kim, C.G.; Ahmad, S.; Malhotra, B.D. Nanostructured iron oxide platform for impedimetric cholesterol detection. Electroanalysis 2010, 22, 1045-1055. [CrossRef]

12. Wang, J.; Carmon, K.S.; Luck, L.A.; Suni, I.I. Electrochemical impedance biosensor for glucose detection utilizing a periplasmic E. coli receptor protein. Electrochem. Solid-State Lett. 2005, 8, H61-H64. [CrossRef]

13. Wang, Y.; Ye, Z.; Ying, Y. New Trends in impedimetric biosensors for the detection of foodborne Pathogenic bacteria. Sensors 2012, 12, 3449-3471. [CrossRef] [PubMed]

14. Radhakrishnan, R.; Suni, I.I.; Bever, C.S.; Hammock, B.D. Impedance biosensors: Applications to sustainability and remaining technical challenges. ACS Sustain. Chem. Eng. 2014, 2, 1649-1655. [CrossRef] [PubMed]

15. Eissa, S.; Jimenez, G.C.; Mahvash, F.; Guermoune, A.; Tlili, C.; Szkopek, T. Functionalized CVD monolayer graphene for label-free impedimetric biosensing. Nano Res. 2014, 8, 1698-1709. [CrossRef]

16. Hu, Y.; Zuo, P.; Ye, B.C. Label-free electrochemical impedance spectroscopy biosensor for direct detection of cancer cells based on the interaction between carbohydrate and lectin. Biosens. Bioelectron. 2013, 43, 79-83. [CrossRef] [PubMed]

17. Wang, C.; Yuan, X.; Liu, X.; Gao, Q.; Qi, H.; Zhang, C. Signal-on impedimetric electrochemical DNA sensor using dithiothreitol modified gold nanoparticle tag for highly sensitive DNA detection. Anal. Chim. Acta 2013, 799, 36-43. [CrossRef] [PubMed]

18. Uygun, Z.O.; Uygun, H.D.E. A short footnote: Circuit design for faradaic impedimetric sensors and biosensors. Sens. Actuators B Chem. 2014, 202, 448-453. [CrossRef]

19. Voitechovič, E.; Bratov, A.; Abramova, N.; Razumienè, J.; Kirsanov, D.; Legin, A. Development of label-free impedimetric platform based on new conductive polyaniline polymer and three-dimensional interdigitated electrode array for biosensor applications. Electrochim. Acta 2015, 173, 59-66. [CrossRef]

20. Craine, J.E.; Connely, J.L. Effect of Hemoglobin on Ferricyanide-Dependent Assays. Anal. Biochem. 1970, 38, 539-546. [CrossRef]

21. Wu, Z.; Liang, J.; Ji, X.; Yang, W. Preparation of uniform $\mathrm{Au} @ \mathrm{SiO}_{2}$ particles by direct silica coating on citrate-capped Au nanoparticles. Colloids Surf. A 2011, 392, 220-224. [CrossRef]

22. Liu, S.H.; Han, M.Y. Synthesis, functionalization, and bioconjugation of monodisperse, silica-coated gold nanoparticles: Robust bioprobes. Adv. Funct. Mater. 2005, 15, 961-967. [CrossRef]

23. Seh, Z.W.; Liu, S.; Zhang, S.-Y.; Shah, K.W.; Han, M.-Y. Synthesis and Multiple Reuse of Eccentric Au@TiO2 Nanostructures as Catalyst. Chem. Commun. 2011, 47, 6689-6691.

24. Briñas, R.P.; Hu, M.; Qian, L.; Lymar, E.S.; Hainfeld, J.F. Gold Nanoparticle Size Controlled by Polymeric Au(I) Thiolate Precursor Size. J. Am. Chem. Soc. 2008, 130, 975-982. [CrossRef] [PubMed]

25. Toh, R.J.; Peng, W.K.; Han, J.; Pumera, M. Direct in vivo electrochemical detection of haemoglobin in red blood cells. Sci. Rep. 2014, 4, 6209. [CrossRef] [PubMed]

26. Zainiharyati, M.Z.; Norazreen, Z. Hydrogen peroxide impedimetric detection on poly-orthophenylenediamine modified platinum disk microelectrode. Malays. J. Anal. Sci. 2014, 18, 107-115.

27. Zhang, L.; Yin, H.-B.; Luo, J.-J.; Yang, P.-H.; Cai, J.Y. Construction of electrochemical impedance sensor basedon poly dopamine-hyaluronic acid composite membranefor detection of hydrogen peroxide. Chin. J. Anal. Chem. 2013, 41, 534-539. [CrossRef]

28. Dhand, C.; Solanki, P.R.; Sood, K.N.; Datta, M.; Malhotra, B.D. Polyaniline nanotubes for impedimetric triglyceride detection. Electrochem. Commun. 2009, 11, 1482-1486. [CrossRef]

29. Zheng, W.; Zheng, Y.F.; Jin, K.W.; Wang, N. Direct electrochemistry and electrocatalysis of hemoglobin immobilized in $\mathrm{TiO}_{2}$ nanotube films. Talanta 2008, 74, 1414-1419. [CrossRef] [PubMed]

30. Tran, H.V.; Huynh, C.D.; Tran, H.V.; Piro, B. Cyclic voltammetry, square wave voltammetry, electrochemical impedance spectroscopy and colorimetric method for hydrogen peroxide detection based on chitosan/silver nanocomposite. Arab. J. Chem. 2016, 1-7. [CrossRef]

31. Nikkhah, E.; Khaiamy, M.; Heidary, R.; Azar, A.S. The effect of ascorbic acid and $\mathrm{H}_{2} \mathrm{O}_{2}$ treatment on the stability of anthocyanin pigments in berries. Turk. J. Biol. 2010, 34, 47-53.

(C) 2017 by the authors. Licensee MDPI, Basel, Switzerland. This article is an open access article distributed under the terms and conditions of the Creative Commons Attribution (CC BY) license (http://creativecommons.org/licenses/by/4.0/). 